\title{
Derxomyces amylogenes sp. nov., Derxomyces bambusicola sp. nov. and Derxomyces corylopsis sp. nov., three ballistoconidium-forming yeast species isolated from subtropical plant leaves
}

Correspondence

Feng-Yan Bai

baify@im.ac.cn
Xin-Zhan Liu, ${ }^{1}$ Qi-Ming Wang, ${ }^{1}$ Teun Boekhout ${ }^{2}$ and Feng-Yan Bai ${ }^{1}$

\author{
${ }^{1}$ State Key Laboratory of Mycology, Institute of Microbiology, \\ Chinese Academy of Science, Beijing 100101, PR China \\ ${ }^{2}$ CBS Fungal Diversity Centre, Royal Netherlands Academy of Arts and Sciences, \\ 3584 CT Utrecht, The Netherlands
}

The genus Bullera is highly polyphyletic and its species belong to the orders Tremellales, Filobasidiales and Trichosporonales (Fell et al., 2000; Fungsin et al., 2006; Nakase et al., 2002; Wang et al., 2004; Scorzetti et al., 2002). Reclassification of Bullera and related genera of basidiomycetous yeasts has been under way and three new genera (Derxomyces, Hannaella and Mingxiaea) have been proposed for the Bullera species that belong to three clades of the Tremellales (Wang \& Bai, 2008; Wang et al., 2011). The number of Derxomyces species that formerly belonged to the Bullera mrakii clade has increased rapidly in recent years (Bai et al., 2001; Wang \& Bai, 2008; Wang et al., 2004 ), suggesting that members of the genus are commonly distributed in nature. Of the currently recognized 20 Derxomyces species, 12 were described from China: seven species from tropical regions, two species from subtropical regions and three species from temperate regions in China (Wang \& Bai, 2008). Compared with tropical and

Abbreviation: ITS, internal transcribed spacer.

The GenBank/EMBL/DDBJ accession numbers for the ITS region and 26S rRNA gene D1/D2 domain sequences of strains $\mathrm{ZJJ}^{\mathrm{N}} 890^{\top}$, ZJJ$394^{\top}$ and $\mathrm{GT}^{\mathrm{T}}-475^{\top}$ are H0890372, HO890374 and H0890376, respectively. temperate regions, subtropical regions of China have rarely been sampled in our study on phylloplane yeast diversity. Therefore, we have increased the number of samples collected from subtropical forests in recent years. Approximately 1700 strains were isolated from 80 plant leaf samples collected in Zhejiang and Hunan provinces located in eastern and central China, respectively. A total of 82 species (including representatives of 27 proposed novel species) belonging to 31 genera of basidiomycetous yeasts were identified based on $26 \mathrm{~S}$ rRNA gene D1/D2 domain sequence analysis. Four of the strains representing three novel Derxomyces species were subjected to further characterization; it is proposed that they are representatives of three novel species, Derxomyces amylogenes sp. nov., Derxomyces bambusicola sp. nov. and Derxomyces corylopsis sp. nov.

The yeast strains studied are listed in Table 1. They were isolated from wilting leaves of different plants by using the improved ballistoconidia-fall method (Nakase \& Takashima, 1993) in July and August, 2010. Morphological, physiological and biochemical characteristics were examined according to standard methods (Yarrow, 1998).

Nuclear DNA was extracted by the method of Makimura et al. (1994). PCR amplification and sequencing of the 
Table 1. Yeast strains studied

\begin{tabular}{|c|c|c|c|}
\hline Species & Strain & Other designation & Source \\
\hline \multirow[t]{2}{*}{ Derxomyces amylogenes sp. nov. } & GT-753 & CGMCC 2.4406 & Leaf of Pinus sp., Gutian Mountain, Zhejiang, China \\
\hline & ZJJ- $890^{\mathrm{T}}$ & $\begin{array}{l}\text { CGMCC } 2.4407^{\mathrm{T}} \\
\text { CBS } 12233^{\mathrm{T}}\end{array}$ & $\begin{array}{l}\text { Leaf of Acer sp., Tianmen Mountain, Zhangjiajie, } \\
\text { Hunan, China }\end{array}$ \\
\hline Derxomyces bambusicola sp. nov. & $\mathrm{GT}-475^{\mathrm{T}}$ & $\begin{array}{l}\text { CGMCC } 2.4411^{\mathrm{T}}, \\
\text { CBS } 12234^{\mathrm{T}}\end{array}$ & $\begin{array}{l}\text { Leaf of bamboo (Phyllostachys heterocycla), Gutian } \\
\text { Mountain, Zhejiang, China }\end{array}$ \\
\hline Derxomyces corylopsis sp. nov. & $\mathrm{ZJJ}-394^{\mathrm{T}}$ & $\begin{array}{l}\text { CGMCC } 2.4409^{\mathrm{T}} \\
\text { CBS } 12259^{\mathrm{T}}\end{array}$ & $\begin{array}{l}\text { Leaf of Corylopsis sp., Tianzi Mountain, Zhangjiajie, } \\
\text { Hunan, China }\end{array}$ \\
\hline
\end{tabular}

DNA fragment covering the internal transcribed spacer (ITS) region (including the 5.8S rRNA gene) and 26S rRNA gene D1/D2 domain were performed using methods described previously (Bai et al., 2002). Sequences were aligned using the program CLUSTAL_X (Thompson et al., 1997). Phylogenetic trees were constructed from evolutionary distance data calculated from Kimura's two-parameter model (Kimura, 1980) by using the neighbour-joining method (Saitou \& Nei, 1987). Bootstrap analyses (Felsenstein, 1985) were performed from 1000 random resamplings.

\section{Phylogenetic analysis}

Phylogenetic analysis based on the combined sequences of the ITS region (including 5.8S rRNA gene) and the $26 \mathrm{~S}$ rRNA gene D1/D2 domain placed strains GT- $475^{\mathrm{T}}$, GT$753, \mathrm{ZJJ}-394^{\mathrm{T}}$ and ZJJ-890 ${ }^{\mathrm{T}}$ in the Derxomyces clade with strong bootstrap support (Fig. 1). Strain GT- $475^{\mathrm{T}}$ was most closely related to Derxomyces linzhiensis, but differed from the latter by $14(2.3 \%)$ mismatches (12 substitutions and 2 indels) in the D1/D2 domain and by 52 (18.2\%) mismatches (29 substitutions and 23 indels) in the ITS region. Strain $\mathrm{ZJJ}-394^{\mathrm{T}}$ was located in a branch together with Derxomyces komagatae, Derxomyces pseudoschimicola and Derxomyces schimicola with $99 \%$ bootstrap support. Strain ZJJ-394 ${ }^{\mathrm{T}}$ differed from these three species by $11-13$ (1.6-1.9\%) mismatches (8-9 substitutions and 3-5 indels) in the D1/D2 domain and 50-74 (15.5-23.0\%) mismatches (25-42 substitutions and 25-32 indels) in the ITS region.

Strains GT-753 and ZJJ-890 ${ }^{\mathrm{T}}$ had identical D1/D2 sequences and differed by only one substitution in the ITS region, thus indicating their conspecificity. They were closely related to Derxomyces boninensis, Derxomyces mrakii and Derxomyces qinlingensis (Fig. 1). They differed from the type strain of $D$. boninensis, the closest relative, by 7 (1.0\%) substitutions in the D1/D2 domain and 38-39 (11.4-11.7\%) mismatches (26 substitutions and 14 indels) in the ITS region.

Compared with the result of Wang \& Bai (2008), addition of the novel strains to the tree drawn from combined D1/D2 and ITS sequences (Fig. 1) slightly changed the positions of a few Derxomyces species, for example, the relative relationships between $D$. linzhiensis, Derxomyces hubeiensis and Derxomyces simaoensis. However, these species still clustered in the same subclade with strong bootstrap support. Likewise, the other subclades of Derxomyces remained stable. The clear separation of the entire clade of Derxomyces from closely related clades was also maintained, supporting the distinction of the genus.

\section{Morphology and physiology}

The four strains studied formed yellowish colonies with butyrous or wrinkled textures, which were similar to the colonies formed by other Derxomyces species (Wang \& Bai, 2008). They reproduced asexually by forming polar or multilateral budding cells and rotationally symmetrical ballistoconidia (Fig. 2). Physiological differences between the novel species and closely related taxa are shown in Table 2. Specifically, strain GT- $475^{\mathrm{T}}$ could be differentiated from its close relative $D$. linzhiensis by assimilation reactions of $\mathrm{D}$-arabinose, $\mathrm{D}$-glucitol, inositol, soluble starch and ethylamine. Strain ZJJ-394 ${ }^{\mathrm{T}}$ could be distinguished from its close relatives by its negative assimilation reactions for D-ribose, L-rhamnose, D-glucitol and inositol and positive assimilation reaction of inulin. Strains GT-753 and ZJJ-890 ${ }^{\mathrm{T}}$ differed from closely related species by their ability to form starch-like substances and to assimilate inulin.

The molecular and phenotypic comparisons described above indicate that the four strains studied represent three novel Derxomyces species, for which the names Derxomyces amylogenes sp. nov. (strains GT-753 and ZJJ-890 ${ }^{\mathrm{T}}$ ), Derxomyces bambusicola sp. nov. (strain GT-475 ${ }^{\mathrm{T}}$ ) and Derxomyces corylopsis sp. nov. (strain $\mathrm{ZJJ}-394^{\mathrm{T}}$ ) are proposed. Although the latter two species are represented by only one strain each, their distinction from close relatives is quite clear (Fig. 1). The formal descriptions of these species will be helpful for understanding the phylogenetic diversity and geographical distribution of species in the recently established genus Derxomyces (Wang \& Bai, 2008).

Latin diagnosis of Derxomyces amylogenes F.-Y. Bai, X.-Z. Liu \& T. Boekhout sp. nov.

In YM (Difco) liquido post dies 7 ad $20{ }^{\circ} \mathrm{C}$, cellulae vegetativae ovoideae aut ellipsoideae, $(2.5-6.5 \times 4.7-10.0 \mu \mathrm{m})$, singulae aut binae. Annulus et sedimentum formantur. In agaro YM post unum mensem ad $20{ }^{\circ} \mathrm{C}$, cultura flavae, non nitida, glabra 


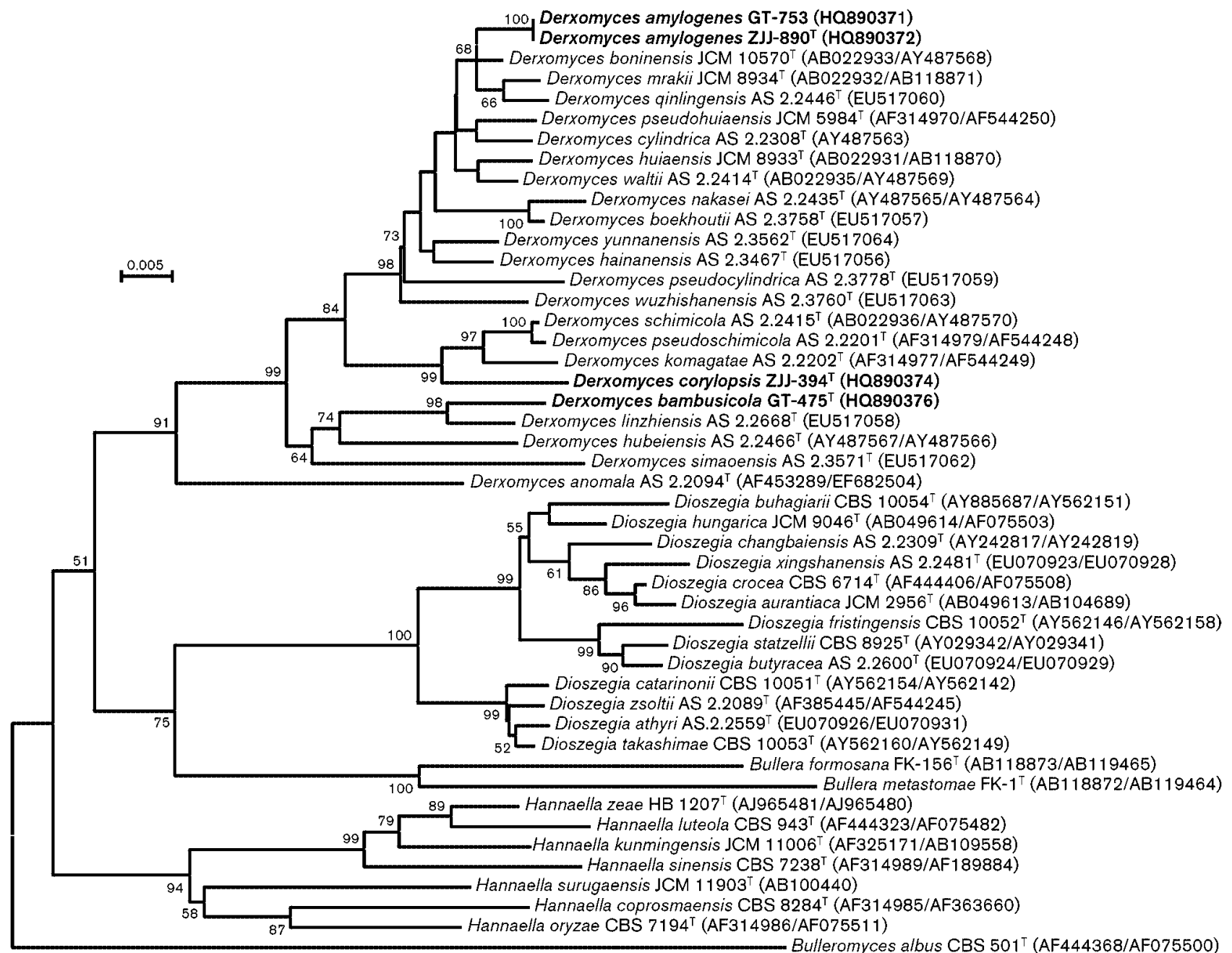

Fig. 1. Phylogenetic tree drawn from neighbour-joining analysis of the combined sequences of the ITS region (including $5.8 S$ rRNA gene) and the 26S rRNA gene D1/D2 domain, depicting the relationship of the three novel Derxomyces species with closely related taxa. Bootstrap percentages below $50 \%$ are not shown. Sequences are from type strains of the species compared, either determined in this study (in bold) or retrieved from GenBank under the accession numbers indicated. Bar, 0.005 substitutions per nucleotide position.

vel rugosa, butyracea, margine glabra. Mycelium et pseudomycelium non formantur. Ballistoconidia subglobosa, ellipsoideae vel napiformia $(5.0-8.7 \times 5.0-8.4 \mu \mathrm{m})$. Fermentatio nulla. Glucosum, galactosum, L-sorbosum (lente et exigue vel infirme), cellobiosum, maltosum, melibiosum, sucrosum, trehalosum, melezitosum, raffinosum, D-arabinosum (lente), L-arabinosum, D-ribosum (vel lente), L-rhamnosum (infirme), D-xylosum, erythritolum (varium), galactitolum (lente et exigue), D-glucitolum (lente et exigue), inositolum (lente vel infirme), D-mannitolum (lente vel infirme), ribitolum (lente et exigue), acidum citricum (vel lente et exigue), acidum succinicum (vel lente), methyl $\alpha$-D-glucoside (vel lente), salicinum (infirme) et inulinum (lente) assimilantur, at non lactosum, ethanolum, glycerolum, methanolum, acidum DLlacticum, D-glucosaminum nec hexadecanum. Ammonium sulfatum, kalium nitricum (lente et exigue) et L-lysinum assimilantur, at non natrum nitrosum, ethylaminum nec cadaverinum. Vitaminae externae ad crescentiam necessaria sunt. Maxima temperatura crescentiae: 25-29 ${ }^{\circ} \mathrm{C}$. Materia amyloidea iodophila formantur. Urea finditur. Diazonium caeruleum B positivum. Typus: ZJJ-890 $80^{\mathrm{T}}$, isolatus ex folio Acer sp., depositus in collectione China General Microbiological Culture Collection Center, Academia Sinica (=CGMCC $2.4407^{\mathrm{T}}=$ CBS $12233^{\mathrm{T}}$ ).

\section{Description of Derxomyces amylogenes F.-Y. Bai, X.-Z. Liu \& T. Boekhout sp. nov.}

Derxomyces amylogenes [a.my.lo.ge' nes. Gr. n. amulon starch; N.L. suff. -genes (from Gr. v. gennaô to produce) producing; N.L. masc. adj. amylogenes starch-producing, referring to the ability of the species to form starch-like compounds]. 

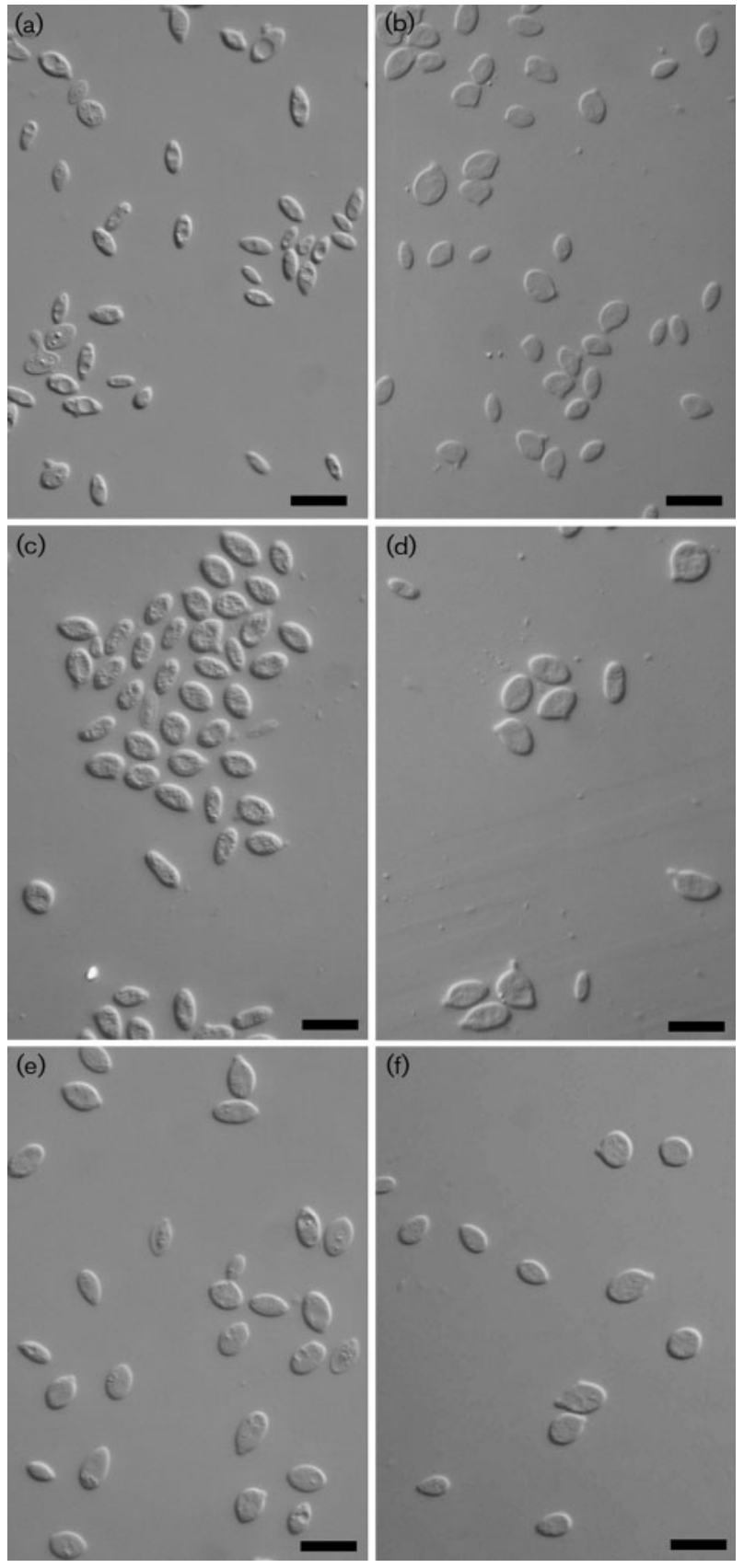

Fig. 2. Vegetative cells (a, c, e) grown in YM broth for 7 days at $20^{\circ} \mathrm{C}$ and ballistoconidia (b, d, f) produced on cornmeal agar after 10 days at $20^{\circ} \mathrm{C}$. $(\mathrm{a}, \mathrm{b})$ Derxomyces amylogenes ZJJ-890'; (c, d) Derxomyces bambusicola GT- $475^{\top}$; (e, f) Derxomyces corylopsis ZJJ-394 ${ }^{\top}$. Bars, $10 \mu \mathrm{m}$.

In YM broth, after 7 days at $20{ }^{\circ} \mathrm{C}$, cells are ovoid and ellipsoidal $(2.5-6.5 \times 4.7-10.0 \mu \mathrm{m})$ (Fig. 2a). Budding is singly or in pairs. Sediment and a ring are formed. On YM agar, after 1 month at $20{ }^{\circ} \mathrm{C}$, the streak culture is yellow, butyrous, dull, smooth or somewhat wrinkled, and has an entire margin. In Dalmau plate culture on cornmeal agar, hyphae and pseudohyphae are not formed. Ballistoconidia are produced on cornmeal agar and are subglobose, ellipsoidal or napiform $(5.0-8.7 \times 5.0-8.4 \mu \mathrm{m})$ (Fig. 2b). Fermentation of glucose is negative. Glucose, galactose, Lsorbose (delayed and weak or slow positive), cellobiose, maltose, melibiose, sucrose, trehalose, melezitose, raffinose, D-arabinose (delayed), L-arabinose, D-ribose (positive or delayed), L-rhamnose (slow positive), D-xylose, erythritol (variable), galactitol (delayed and weak), Dglucitol (delayed and weak), inositol (delayed or slow positive), D-mannitol (delayed or slow positive), ribitol (delayed and weak), citric acid (positive or delayed and weak), succinic acid (positive or delayed), methyl $\alpha$-Dglucoside (positive or delayed), salicin (slow positive), inulin (delayed) are assimilated. Lactose, ethanol, glycerol, methanol, DL-lactic acid, D-glucosamine and hexadecane are not assimilated. Ammonium sulfate, potassium nitrate (delayed and weak) and L-lysine are assimilated. Sodium nitrite, ethylamine hydrochloride and cadaverine dihydrochloride are not assimilated. Maximum growth temperature is $25-29{ }^{\circ} \mathrm{C}$. Growth in vitamin-free medium is negative. Starch-like compounds are produced. Urease activity is positive. Diazonium blue B reaction is positive.

The type strain is $\mathrm{ZJJ}-890^{\mathrm{T}}\left(=\mathrm{CGMCC} 2.4407^{\mathrm{T}}=\mathrm{CBS}\right.$ $\left.12233^{\mathrm{T}}\right)$, isolated from a wilting leaf of Acer sp. collected in Tianmen Mountain, Zhangjiajie, Hunan Province in August 2010.

\section{Latin diagnosis of Derxomyces bambusicola F.-Y. Bai, X.-Z. Liu \& T. Boekhout sp. nov.}

In YM (Difco) liquido post dies 7 ad $20{ }^{\circ} \mathrm{C}$, cellulae vegetativae ovoideae, ellipsoideae aut cylindrarae (3.7$5.5 \times 7.5-12.0 \mu \mathrm{m})$, singulae. Annulus et sedimentum formantur. In agaro YM post unum mensem ad $20{ }^{\circ} \mathrm{C}$, cultura flavae, non nitida, glabra, butyracea, margine glabra. Mycelium et pseudomycelium non formantur. Ballistoconidia napiformia $(4.7-7.5 \times 5.0-8.5 \mu \mathrm{m})$. Fermentatio nulla. Glucosum, galactosum, cellobiosum, maltosum, melibiosum, sucrosum, trehalosum, melezitosum, raffinosum, L-arabinosum, L-rhamnosum (lente et exigue), D-xylosum (lente), galactitolum (lente), D-mannitolum, acidum succinicum, methyl $\alpha$-D-glucoside (lente), salicinum (lente) et inulinum assimilantur, at non L-sorbosum, lactosum, D-arabinosum, Dribosum, ethanolum, erythritolum, D-glucitolum, glycerolum, inositolum, methanolum, ribitolum, acidum citricum, acidum DL-lacticum, D-glucosaminum nec hexadecanum. Ammonium sulfatum, kalium nitricum (lente et exigue), L-lysinum (lente) et ethylaminum assimilantur, at non natrum nitrosum nec cadaverinum. Vitaminae externae ad crescentiam necessaria sunt. Maxima temperatura crescentiae: $29^{\circ} \mathrm{C}$. Materia amyloidea iodophila non formantur. Urea finditur. Diazonium caeruleum B positivum. Typus: GT- $475^{\mathrm{T}}$, isolatus ex folio Phyllostachys heterocycla, depositus in collectione China General Microbiological Culture Collection Center, Academia Sinica $\left(=\right.$ CGMCC $2.4411^{\mathrm{T}}=$ CBS $\left.12234^{\mathrm{T}}\right)$. 
Table 2. Physiological characteristics that differentiate the three novel Derxomyces species from closely related taxa

Group I species: 1, D. amylogenes sp. nov.; 2, D. boninensis; 3, D. mrakii; 4, D. qinlingensis. Group II species: 1, D. bambusicola sp. nov.; 2, D. linzhiensis. Group III species: 1, D. corylopsis sp. nov.; 2, D. komagatae; 3, D. pseudoschimicola; 4, D. schimicola. +, Positive; -, negative; 1, delayed; s, slow positive; w, weak; lw, delayed and weak; where more than one symbol appears in a cell, all characteristics may be observed.

\begin{tabular}{|c|c|c|c|c|c|c|c|c|c|c|}
\hline \multirow[t]{2}{*}{ Characteristic } & \multicolumn{4}{|c|}{ Group I } & \multicolumn{2}{|c|}{ Group II } & \multicolumn{4}{|c|}{ Group III } \\
\hline & 1 & 2 & 3 & 4 & 1 & 2 & 1 & 2 & 3 & 4 \\
\hline \multicolumn{11}{|l|}{ Assimilation of: } \\
\hline D-Arabinose & 1 & + & + & + & - & + &,$+ \mathrm{w}$ & 1 &,+ 1 & + \\
\hline D-Ribose & $1,+$ & + & + & + & - & - & - & 1 & 1 & + \\
\hline L-Rhamnose & s & + & + & + & lw & - & - & 1 &,+ 1 & + \\
\hline D-Glucitol & lw &,+ 1 & $\mathrm{w},-$ & - & - & + & - & + &,+- & + \\
\hline Inositol & $1, \mathrm{~s}$ &,+ 1 & + & + & - & $\mathrm{w}$ & - & 1 & $+, 1, \mathrm{w}$ & + \\
\hline D-Mannitol & $1, \mathrm{~s}$ &,+ 1 & 1 & - & + & + & $\mathrm{s}, 1$ & 1 &,+ 1 & + \\
\hline Salicin & $\mathrm{s}$ & + & + & + & 1 & - & $\mathrm{lw}$ & + & $+, \mathrm{l}, \mathrm{w}$ & + \\
\hline Inulin & 1 & - & - & - & + & + & 1 & - & - & - \\
\hline Soluble starch & $\mathrm{s}, 1$ & + & + & - & + & - & 1 & + & + & + \\
\hline L-Lysine & + & + & + & + & 1 & + & 1 & + & + & + \\
\hline Ethylamine & - & - & - & - & + & - & - & - & - & - \\
\hline Starch formation & + & - & - & - & - & - & - & - & - & - \\
\hline
\end{tabular}

\section{Description of Derxomyces bambusicola F.-Y. Bai, X.-Z. Liu \& T. Boekhout sp. nov.}

Derxomyces bambusicola [bam.bu.si' co.la. N.L. n. Bambusa scientific name of bamboo; L. suff. -cola (from L. n. incola) inhabitant, dweller; N.L. n. bambusicola bamboo dweller, referring to the source of the type strain of the species].

In YM broth, after 7 days at $20{ }^{\circ} \mathrm{C}$, cells are ovoid, ellipsoidal and cylindrical $(3.7-5.5 \times 7.5-12.0 \mu \mathrm{m})$ (Fig. 2c). Budding is singly. Sediment and a ring are formed. On YM agar, after 1 month at $20{ }^{\circ} \mathrm{C}$, the streak culture is yellow, butyrous, dull and smooth, with an entire margin. In Dalmau plate culture on cornmeal agar, hyphae and pseudohyphae are not formed. Ballistoconidia are produced on cornmeal agar and are napiform, $(4.7-7.5 \times 5.0-8.5 \mu \mathrm{m})$ (Fig. $2 \mathrm{~d}$ ). Fermentation of glucose is negative. Glucose, galactose, cellobiose, maltose, melibiose, sucrose, trehalose, melezitose, raffinose, L-arabinose, L-rhamnose (delayed and weak), D-xylose (delayed), galactitol (delayed), D-mannitol, succinic acid, methyl $\alpha$-Dglucoside (delayed), salicin (delayed) and inulin are assimilated. L-Sorbose, lactose, D-arabinose, D-ribose, ethanol, erythritol, D-glucitol, glycerol, inositol, methanol, ribitol, citric acid, DL-lactic acid, D-glucosamine and hexadecane are not assimilated. Ammonium sulfate, potassium nitrate (delayed and weak), L-lysine (delayed) and ethylamine hydrochloride are assimilated. Sodium nitrite and cadaverine dihydrochloride are not assimilated. Maximum growth temperature is $29^{\circ} \mathrm{C}$. Growth in vitamin-free medium is negative. Starch-like compounds are not produced. Urease activity is positive. Diazonium blue $\mathrm{B}$ reaction is positive.

The type strain is GT- $475^{\mathrm{T}}$ (=CGMCC $2.4411^{\mathrm{T}}=\mathrm{CBS}$ $12234^{\mathrm{T}}$ ), isolated from a wilting leaf of Phyllostachys heterocycla collected in Gutian Mountain, Zhejiang Province, China in July 2010.

\section{Latin diagnosis of Derxomyces corylopsis F.-Y. Bai, X.-Z. Liu \& T. Boekhout sp. nov.}

In YM (Difco) liquido post dies 7 ad $20{ }^{\circ} \mathrm{C}$, cellulae vegetativae ovoideae aut ellipsoideae $(2.5-6.2 \times 5.0-10.0 \mu \mathrm{m})$, singulae. Annulus et sedimentum formantur. In agaro YM post unum mensem ad $20{ }^{\circ} \mathrm{C}$, cultura flavae, non nitida, rugosa, butyracea, margine glabra. Pseudomycelium formantur. Ballistoconidia subglobosa, ellipsoideae vel napiformia $(5.0-7.5 \times 5.0-9.4 \mu \mathrm{m})$. Fermentatio nulla. Glucosum, galactosum, cellobiosum, maltosum, melibiosum, sucrosum (vel infirme), trehalosum, melezitosum, raffinosum, D-arabinosum (vel exigue), L-arabinosum, D-xylosum, galactitolum (varium), D-mannitolum (infirme vel lente), ribitolum (lente et exigue), acidum succinicum, methyl $\alpha$-D-glucoside (infirme), salicinum (lente et exigue) et inulinum (lente) assimilantur, at non L-sorbosum, lactosum, D-ribosum, L-rhamnosum, ethanolum, erythritolum, D-glucitolum, glycerolum, inositolum, methanolum, acidum citricum, acidum DL-lacticum, D-glucosaminum nec hexadecanum. Ammonium sulfatum, kalium nitricum (lente et exigue) et L-lysinum (lente) assimilantur, at non natrum nitrosum, ethylaminum nec cadaverinum. Vitaminae externae ad crescentiam necessaria sunt. Maxima temperatura crescentiae: $29{ }^{\circ} \mathrm{C}$. Materia amyloidea iodophila non formantur. Urea finditur. Diazonium caeruleum B positivum. Typus: ZJJ-394 ${ }^{\mathrm{T}}$, isolatus ex folio Corylopsis sp., depositus in collectione China General Microbiological Culture Collection Center, Academia Sinica $\left(=\right.$ CGMCC $2.4409^{\mathrm{T}}=$ CBS $\left.12259^{\mathrm{T}}\right)$.

\section{Description of Derxomyces corylopsis F.-Y. Bai, X.-Z. Liu \& T. Boekhout sp. nov.}

Derxomyces corylopsis (co.ryl'op.sis. N.L. gen. n. corylopsis of Corylopsis, isolated from a wilting leaf of Corylopsis sp.). 
In $\mathrm{YM}$ broth, after 7 days at $20{ }^{\circ} \mathrm{C}$, cells are ovoid and ellipsoidal $(2.5-6.2 \times 5.0-10.0 \mu \mathrm{m})$ (Fig. 2e). Budding is singly. Sediment and a ring are formed. On YM agar, after 1 month at $20{ }^{\circ} \mathrm{C}$, the streak culture is yellow, butyrous, dull and wrinkled. The margin is entire. In Dalmau plate culture on cornmeal agar, pseudohyphae are formed. Ballistoconidia are produced on cornmeal agar, which are subglobose, ellipsoidal or napiform $(5.0-7.5 \times 5.0-9.4 \mu \mathrm{m})$ (Fig. 2f). Fermentation of glucose is negative. Glucose, galactose, cellobiose, maltose, melibiose, sucrose (positive or slow positive), trehalose, melezitose, raffinose, Darabinose (positive or weak), L-arabinose, D-xylose, galactitol (variable), D-mannitol (slow positive or delayed), ribitol (delayed and weak), succinic acid, methyl $\alpha$-Dglucoside (slow positive), salicin (delayed and weak) and inulin (delayed) are assimilated. L-Sorbose, lactose, Dribose, L-rhamnose, ethanol, erythritol, D-glucitol, glycerol, inositol, methanol, citric acid, DL-lactic acid, D-glucosamine and hexadecane are not assimilated. Ammonium sulfate, potassium nitrate (delayed and weak) and L-lysine (delayed) are assimilated. Sodium nitrite, ethylamine hydrochloride and cadaverine dihydrochloride are not assimilated. Maximum growth temperature is $29^{\circ} \mathrm{C}$. Growth in vitamin-free medium is negative. Starch-like compounds are not produced. Urease activity is positive. Diazonium blue B reaction is positive.

The type strain is $\mathrm{ZJJ}-394^{\mathrm{T}}\left(=\mathrm{CGMCC} 2.4409^{\mathrm{T}}=\mathrm{CBS}\right.$ $12259^{\mathrm{T}}$ ), isolated from a wilting leaf of Corylopsis sp. collected in Tianzi Mountain, Zhangiajie, Hunan Province in August 2010.

\section{Acknowledgements}

This study was supported by grants from the National Natural Science Foundation of China (NSFC), China (grant nos 30825002 and 31010103902) and from the Royal Netherlands Academy of Arts and Sciences (KNAW), The Netherlands (grant no. 10CDP019).

\section{References}

Bai, F.-Y., Takashima, M. \& Nakase, T. (2001). Phylogenetic analysis of strains originally assigned to Bullera variabilis: descriptions of Bullera pseudohuiaensis sp. nov., Bullera komagatae sp. nov. and Bullera pseudoschimicola sp. nov. Int J Syst Evol Microbiol 51, 2177-2187.

Bai, F.-Y., Zhao, J.-H., Takashima, M., Jia, J.-H., Boekhout, T. \& Nakase, T. (2002). Reclassification of the Sporobolomyces roseus and Sporidiobolus pararoseus complexes, with the description of Sporobolomyces phaffii sp. nov. Int J Syst Evol Microbiol 52, 2309-2314.

Fell, J. W., Boekhout, T., Fonseca, A., Scorzetti, G. \& StatzellTallman, A. (2000). Biodiversity and systematics of basidiomycetous yeasts as determined by large-subunit rDNA D1/D2 domain sequence analysis. Int J Syst Evol Microbiol 50, 1351-1371.

Felsenstein, J. (1985). Confidence limits on phylogenies: an approach using the bootstrap. Evolution 39, 783-791.

Fungsin, B., Takashima, M., Sugita, T., Artjariyasripong, S., Potacharoen, W., Tanticharoen, M. \& Nakase, T. (2006). Bullera koratensis sp. nov. and Bullera lagerstroemiae sp. nov., two new ballistoconidium-forming yeast species in the Trichosporonales clade isolated from plant leaves in Thailand. J Gen Appl Microbiol 52, 73-81.

Kimura, M. (1980). A simple method for estimating evolutionary rates of base substitutions through comparative studies of nucleotide sequences. J Mol Evol 16, 111-120.

Makimura, K., Murayama, S. Y. \& Yamaguchi, H. (1994). Detection of a wide range of medically important fungi by the polymerase chain reaction. J Med Microbiol 40, 358-364.

Nakase, T. \& Takashima, M. (1993). A simple procedure for the high frequency isolation of new taxa of ballistosporous yeasts living on the surfaces of plants. RIKEN Rev 3, 33-34.

Nakase, T., Tsuzuki, S. \& Takashima, M. (2002). Bullera taiwanensis sp nov and Bullera formosensis sp. nov., two new ballistoconidiumforming yeast species isolated from plant leaves in Taiwan. J Gen Appl Microbiol 48, 345-355.

Saitou, N. \& Nei, M. (1987). The neighbor-joining method: a new method for reconstructing phylogenetic trees. Mol Biol Evol 4, 406425.

Scorzetti, G., Fell, J. W., Fonseca, A. \& Statzell-Tallman, A. (2002). Systematics of basidiomycetous yeasts: a comparison of large subunit D1/D2 and internal transcribed spacer rDNA regions. FEM Yeast Res 2, 495-517.

Thompson, J. D., Gibson, T. J., Plewniak, F., Jeanmougin, F. \& Higgins, D. G. (1997). The CLUSTAL_X windows interface: flexible strategies for multiple sequence alignment aided by quality analysis tools. Nucleic Acids Res 25, 4876-4882.

Wang, Q.-M. \& Bai, F.-Y. (2008). Molecular phylogeny of basidiomycetous yeasts in the Cryptococcus luteolus lineage (Tremellales) based on nuclear rRNA and mitochondrial cytochrome $b$ gene sequence analysis: proposal of Derxomyces gen. nov. and Hannaella gen. nov., and description of eight novel Derxomyces species. FEM Yeast Res $\mathbf{8}$, 799-814.

Wang, Q.-M., Bai, F.-Y., Lu, H.-Z., Jia, J.-H. \& Takashima, M. (2004). Bullera cylindrica sp. nov., Bullera hubeiensis sp. nov. and Bullera nakasei sp. nov., ballistoconidium-forming yeast species from plant leaves. Int J Syst Evol Microbiol 54, 1877-1882.

Wang, Q.-M., Bai, F.-Y., Fungsin, B., Boekhout, T. \& Nakase, T. (2011). Proposal of Mingxiaea gen. nov. for the anamorphic basidiomycetous yeast species in the Bulleribasidium clade (Tremellales) based on molecular phylogenetic analysis, with six new combinations and four novel species. Int J Syst Evol Microbiol 61, 210-219.

Yarrow, D. (1998). Methods for the isolation, maintenance and identification of yeasts. In The Yeasts, a Taxonomic Study, 4th edn, pp. 77-100. Edited by C. P. Kurtzman \& J. W. Fell. Amsterdam: Elsevier. 